\title{
Small bowel through the canal of nuck causing urinary retention
}

\author{
Nikolaos Kochylas*, Riad Nafas \\ $4^{\text {th }}$ Surgical Department, "Evaggelismos" General Hospital, Athens, Greece
}

Received: September 19, 2016

DOI: $10.5430 / \operatorname{css} . v 3 n 1 \mathrm{p} 10$
Accepted: October 23, 2016

URL: http://dx.doi.org/10.5430/css.v3n1p10

\begin{abstract}
The differential diagnosis of indirect inguinal hernia in women can be a challenge to the surgeon as symptoms can vary from chronic pelvic pain to even a palpable labial mass. Indirect inguinal hernia is usually congenital, and a patent canal of Nuck can complicate a hernia with hydrocele. Contents of the hernia sack include small bowel, part of the urinary bladder, or an ovary. This is a case report of an indirect inguinal hernia in a 57-year-old woman presented as a labial mass that caused intermittent urinary retention for a year before she decided to seek medical attention. After a CT scan that confirmed the diagnosis of hernia, the patient underwent a herniorrhaphy with a plug mesh. The sack contained small bowel. After the herniorrhaphy the urinary symptoms disappeared. In conclusion, an inguinal hernia can present as a labial mass causing urinary symptoms without including the bladder or ureter.
\end{abstract}

Key Words: Inguinal hernia, Labial mass, Nuck, Urinary retention, Indirect

\section{INTRODUCTION}

Inguinal hernia in women is not documented enough in literature, although they comprise about $9 \%$ of all herniorrhaphies. ${ }^{[1]}$ Indirect inguinal hernia is the most common hernia in women, ${ }^{[2]}$ presenting frequently as a mass in the labia major and, in pediatric literature, has been reported to contain an ovary. ${ }^{[3]}$ Another, less frequent, reason for a labian mass is the hydrocele of the canal of Nuck. ${ }^{[4]}$ One third of these hydroceles is accompanied by an inguinal hernia. ${ }^{[5]}$ This study is a case report of a female patient with an indirect inguinal hernia through a patent canal of Nuck that caused intermittent urinary retention.

\section{Case PResentation}

A 57-year-old woman presented with a 1-year history of intermittent urinary failure to void and a palpable nonreducible mass in the right labia major, at the level of the inguinofemoral crease. Medical history included arterial hypertension and dyslipidemia. Surgical history: left herniorraphy 3 years earlier, total thyroidectomy 7 years earlier. History of 2 full term natural deliveries CT scan of the pelvis revealed a fat-density mass descending from the ingunal region down to the labia majora (see Figures 1-2).

The patient was scheduled for open herniorraphy. The findings were a $15 \mathrm{~cm}$ long hernia sac running from the internal inguinal ring anteriorly of the round ligament, till the lower part of labia major. The sac was separated from the round ligament of the uterus and opened, revealing a loop of small bowel. It was ligated at the internal inguinal ring. A coneshaped mesh was inserted into the internal ring opening and fixed with 4 prolene sutures. The external oblique aponeurosis was closed with interrupted sutures. The postoperative course was uneventful and the patient was discharged on the $2^{\text {nd }}$ postoperative day.

*Correspondence: Nikolaos Kochylas; Email: nickkohilas1979@ hotmail.com; Address: Kremou str. 120, Kallithea P.O box 17676, Athens, Greece. 


\section{DISCUSSION}

Although the absence of a spermatic cord makes the anatomy of the female inguinal region easier surgeons are not as familiar with it, as with the male counterpart. The embryological basis of the canal of Nuck lies in the processus vaginalis, a fold of parietal peritoneum that forms in the 6th month of gestation. Guided by the gubernaculum, it terminates in the labia majora. It normally disappears around birth by fusing with the gubernaculum to form the round ligament of the uterus. $^{[3]}$ If that doesn't happen, a patent processus vaginalis forms the canal of Nuck. Though it, peritoneal fluid can cause a hydrocele, or abnormal descending bowel, ovary or bladder can cause an indirect inguinal hernia. ${ }^{[4,6]}$ Although it first appeared in the literature as presentations of congenital or pediatric conditions, the awareness of the patent canal of Nuck has spread to the adult population. ${ }^{[7]}$ Its clinical manifestations, chronic pelvic pain and a labial mass continue to confound surgeons to this day. ${ }^{[8]}$ Sonography can prove to be a useful ally. ${ }^{[9]}$ And finally, urinary symptoms have been described as part of hernias containing part of the bladder or ureter, ${ }^{[10]}$ but not bowel.

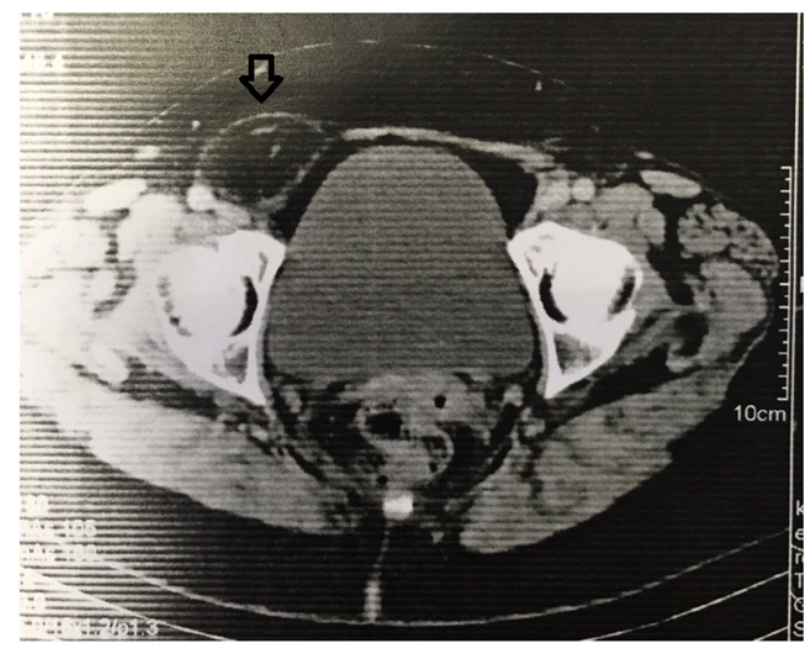

Figure 1. Mass with fat density in the right inguinal region (arrow)

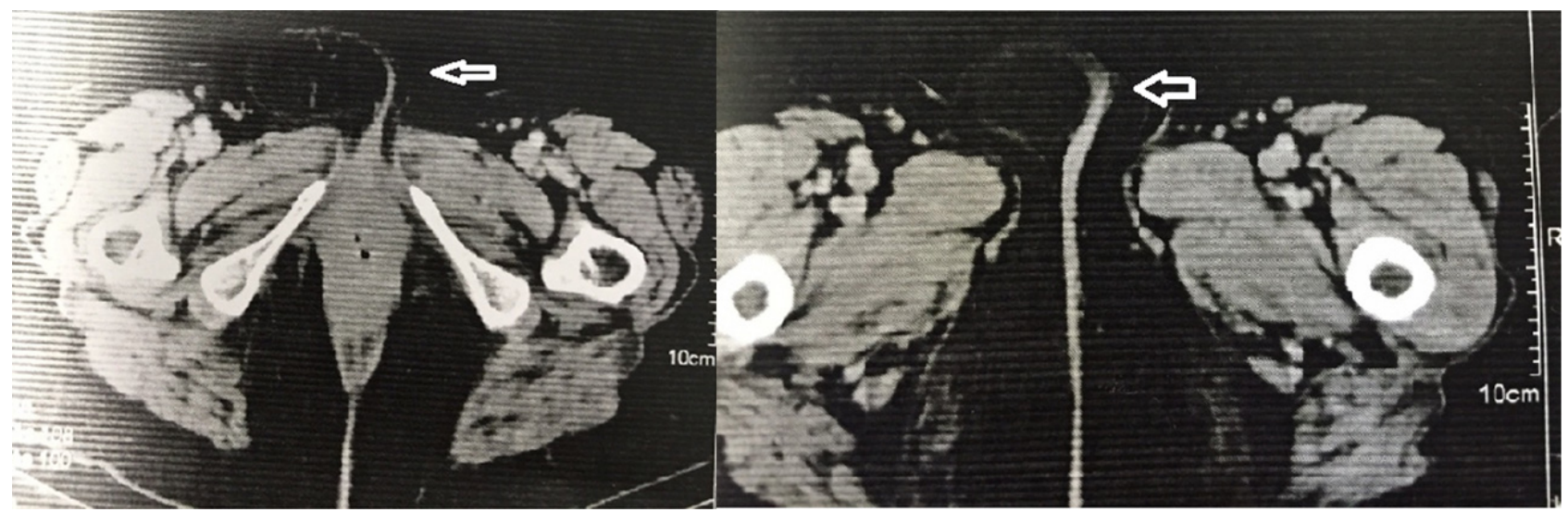

Figure 2. The same mass descending into the right labia major (arrows)

This case report combines many of the rarities and unique characteristics of the female inguinal canal, that an indirect hernia containing small bowel, in an adult woman, through a patent canal of Nuck, is causing urinary retention symptoms by lateral pressure on the urethra.

\section{Conflicts of InTEREST Disclosure}

The authors declare that they have no competing interests.

\section{REFERENCES}

[1] Morten B, Henrik K. Inguinal herniorrhaphy in women. Hernia. 2006; 10: 30-33. https://doi.org/10.1007/s10029-005-0029-3

[2] Weber A, Valencia S, Garteiz D, et al. Epidemiology of hernias in the female. In: Bendavid R et al (eds) Abdominal wall Hernias. Berlin Heidelberg New York: Springer; 2001. Chapter 88, Table 2: 614 p.

[3] Huang CS, Luo CC, Chao HC, et al. The presentation of asymptomatic palpable movable mass in female inguinal hernia. Eur J Pediatr. 2003; 162: 493-495. https://doi.org/10.1007/s004

\section{1-003-1226-7}

[4] Ozbey H, Ratschek M, Schimple G, et al. Ovary in hernia sac: prolapsed or a descended gonad? J Pediatr Surg. 1999; 34: 977-980. https://doi.org/10.1016/S0022-3468(99) 90772-8

[5] Anderson CC, Broadie TA, Mackey JE, et al. Hydrocele of the canal of Nuck: ultrasound appearance. Am Surg. 1995; 61: 959-961. PMid: 7486426 .

[6] Kucera P, Glazer J. Hydrocele of the canal of Nuck. A report of four cases. J Reprod Med. 1985; 30: 439-442. PMid: 3925139. 
[7] Graul A, Ko E. Indirect Inguinal Hernia Containing a Fallopian Tube and Ovary in a Reproductive Aged Woman. Case Reports in Obstetrics and Gynecology. 2014; https://doi.org/10.1155/2014/4 37340

[8] Perry P, Echeverri J. Hernias as a Cause of Chronic Pelvic Pain in Women. JSLS. 2006; 10: 212-215. PMid: 16882422.
[9] Grant T, Neuschler E, Hartz W. Sonography of Occult Hernias in Women With Groin Pain. J Ultrasound Med. 2011; 30: 1701-1707. PMid: 22124006.

[10] Tubbs R, Loukas M, Shoja M, et al. Indirect inguinal hernia of the urinary bladder through a persistent canal of Nuck: case report. Hernia. 2007; 11: 287-288. https://doi.org/10.1007/s10029-0 07-0192-9 